\title{
Preliminary test results of radial- type sintered Sm-123 bulk motor
}

\author{
$\operatorname{AUTHOR}(S):$ \\ Jung, HJ; Nakamura, T; Miyake, H; Muta, I; Hoshino, \\ $\mathrm{T}$
}

\section{CITATION:}

Jung, HJ ... [et al]. Preliminary test results of radial-type sintered Sm-123 bulk motor. IEEE TRANSACTIONS ON APPLIED SUPERCONDUCTIVITY 2005, 15(2): 2198-2201

\section{ISSUE DATE:}

2005-06

URL:

http://hdl.handle.net/2433/39962

\section{RIGHT:}

(c)2005 IEEE. Personal use of this material is permitted. However, permission to reprint/republish this material for advertising or promotional purposes or for creating new collective works for resale or redistribution to servers or lists, or to reuse any copyrighted component of this work in other works must be obtained from the IEEE. 


\title{
Preliminary Test Results of Radial-Type Sintered Sm-123 Bulk Motor
}

\author{
Hun-June Jung, Taketsune Nakamura, Hironori Miyake, Itsuya Muta, and Tsutomu Hoshino
}

\begin{abstract}
We designed and fabricated a radial-type motor with a high temperature superconducting bulk rotor. The fabricated motor has 3-phase and 4-pole armature winding, and then generates rotating magnetic field at the speed of $1800 \mathrm{rpm}$ under the condition of 3-phase, $60 \mathrm{~Hz}$ electric power. Sintered $\mathrm{Sm}-123$ bulk was utilized for the solid rotor in this study. The performance of the sintered Sm-123 bulk motor was evaluated by no-load, locked-rotor and load test. Test results showed that the motor generated a little torque and rotated with large slip, even if the motor was applied $165 \mathrm{~V}_{\mathrm{rms}}$ of the phase voltage (the stator current is $18 \mathrm{~A}_{\mathrm{rms}}$ ). Because of small magneto-motive-force and spatial harmonic components in the air-gap, magnetic flux was prevented from penetrating into the HTS bulk rotor. Therefore, the screening current in the rotor flowed only at the surface of the rotor and generated torque is remained in a little value.
\end{abstract}

Index Terms-High temperature superconducting (HTS) bulk motor, radial type motor, sintered Sm-123 bulk.

\section{INTRODUCTION}

B ECAUSE of the higher critical temperature of high temperature superconductor (HTS), its applications have the advantage in cooling compared to the counterparts of a low temperature superconductor (LTS). Therefore, superconducting technology can be applicable to the middle and small size electric power apparatus owing to the cooling load mitigation, which is achieved by the use of HTS. Especially, HTS bulk material is expected to apply to magnetic bearing, flywheel energy storage system, motor, and so on, with the aid of the improvement of its critical current density and mechanical solidity. Among such applications, some types of HTS bulk motor, i.e., hysteresis, reluctance, and trapped-flux type, have been proposed, and their performance improvement and large sizing studies are in progress [1]-[9].

Generally, Re-123 material that has the strong pinning property at $77 \mathrm{~K}$ is used in HTS bulk motors. On the other hand, we have examined not only Re-123 but also Bi-2223 material with the object of applicability study. Axial-type Sm-123 and Bi-2223 bulk motors were fabricated, and their performances

Manuscript received October 5, 2004. This work has been supported by the Ube Foundation, Fundamental Research Developing Association for Shipbuilding and Offshore (REDAS) and Grant-in-Aid for Scientific Research (no. 13450113) from the Ministry of Education, Culture, Sports, Science and Technology in Japan. This work has also been carried out as a project of the 21st Century COE Program (no. 14213201) in Japan.

H.-J. Jung, T. Nakamura, H. Miyake, and T. Hoshino are with the Department of Electrical Engineering, Kyoto University, Kyoto 615-8510, Japan (e-mail: hjjung@asl.kuee.kyoto-u.ac.jp; tk_naka@kuee.kyoto-u.ac.jp; miyake@asl.kuee.kyoto-u.ac.jp; hoshino@asl.kuee.kyoto-u.ac.jp).

I. Muta is with Saga University, Saga 840-8502, Japan (e-mail: muta128@bb.excite.co.jp).

Digital Object Identifier 10.1109/TASC.2005.849611

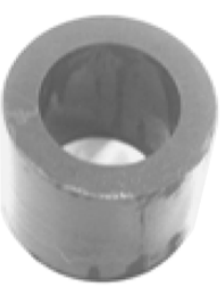

(a)

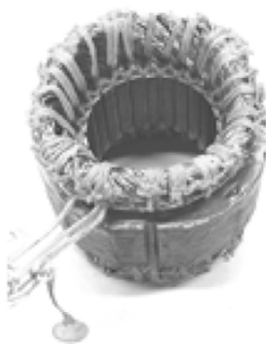

(b)

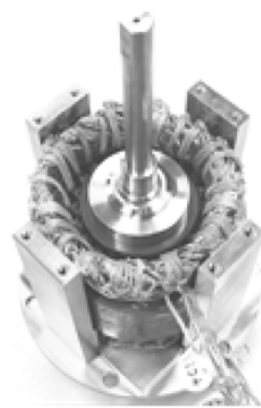

(c)
Fig. 1. Photographs of rotor, stator and Sm-123 bulk motor. (a) Sm-123 bulk rotor; (b) stator; (c) radial-type Sm-123 bulk motor.

TABLE I

SPECIFICATIONS OF HTS BULK

\begin{tabular}{clc}
\hline \hline \multicolumn{1}{c}{ Item } & Value \\
\hline sintered Sm-123 & outer diameter, $\mathrm{mm}$ & 59 \\
& bored diameter, $\mathrm{mm}$ & 39 \\
& height, $\mathrm{mm}$ & 50 \\
\hline
\end{tabular}

were evaluated by tests [10]-[17]. Especially, we investigated the electromagnetic phenomenon inside HTS bulk rotors in a rotating magnetic field, and then discussed the torque generation mechanism of HTS bulk motor.

The axial-type motor is easier to fabricate because of a simple structure. Moreover, this structure is convenient to investigate the electromagnetic phenomenon inside the rotor using a Hall sensor. However, the axial-type motor has poor efficiency and problem in load connection. Therefore, it is regarded that a radial-type motor is superior to the axial-type motor from the viewpoint of application.

In this study, a radial type Sm-123 bulk motor is designed and fabricated, and its preliminary characteristics are evaluated.

\section{Structure OF RADial-TyPe Sm-123 BulK Motor}

The radial-type Sm-123 bulk motor consists of a conventional stator and a Sm-123 bulk rotor. Fig. 1 shows photographs of (a) Sm-123 bulk rotor, (b) 3-phase, 4-pole stator, and (c) fabricated radial-type $\mathrm{Sm}-123$ bulk motor, respectively.

The Sm-123 bulk rotor was manufactured by sintered process in the shape of cylinder. Specifications of the sintered Sm-123 rotor are shown in Table I. As shown in the table, the thickness of the Sm-123 cylinder is $10 \mathrm{~mm}$.

The stator has a semi-enclosed 24-slotted iron core and a 3 -phase armature winding. The stator generates 4-pole rotating magnetic field at the speed of $1800 \mathrm{rpm}$ under the condition of 
TABLE II

SPECIFICATIONS OF STATOR

\begin{tabular}{clc}
\hline \hline Item & Value \\
\hline laminated core & outer diameter, $\mathrm{mm}$ & 104.5 \\
& inner diameter, $\mathrm{mm}$ & 60 \\
& height, $\mathrm{mm}$ & 39.6 \\
\hline
\end{tabular}

3-phase, $60 \mathrm{~Hz}$ electric power. Specifications of the stator are shown in Table II.

The radial-type motor is constructed with the sintered Sm-123 bulk rotor (Fig. 1(a)) and the stator (Fig. 1(b)) as shown in Fig. 1(c). The rotor shaft passes through the bore of the bulk rotor, and is fixed with brass ring. The air-gap length is set to $0.5 \mathrm{~mm}$ and the overhang length is set to $5.2 \mathrm{~mm}$ in each side. A ball bearing is used for supporting the rotor shaft. The whole motor system is immersed in liquid nitrogen for cooling the HTS bulk rotor during experiment.

\section{EXPERIMENTAL}

\section{A. Air-Gap Magnetic Flux Density Distribution}

The air-gap magnetic flux density distribution is measured by the transverse-type Hall sensor that is mounted on the surface of dummy rotor (nonmagnetic and nonconductive material) at room temperature. Therefore, the influence of induced current in the HTS bulk rotor is not included in measured results. Under the condition of 3-phase, $60 \mathrm{~Hz}, 1 \mathrm{~A}_{\mathrm{rms}}$ electric power, magnetic flux density is measured by rotating the dummy rotor at every $1^{\circ}$ angular interval over $180^{\circ}$ range. Hall signal is recorded by a transient recorder with the armature current after amplified. The spatial distribution of the magnetic flux density is obtained from the measured magnetic flux density by arranging armature current waveforms in the same phase. Using the measured $180^{\circ}$ range result, total range distribution $\left(360^{\circ}\right)$ is expressed by changing the direction of waveform. The magnetic flux density distribution is analyzed using Fast Fourier Transform (FFT), and harmonic components are obtained.

\section{B. Performance Evaluation of Sintered Sm-123 Bulk Motor}

The motor is installed in a metal cryostat, and immersed in liquid nitrogen with zero-field-cooling process. Thereafter, no-load, locked rotor, and load tests are carried out under the condition of 3-phase, $60 \mathrm{~Hz}$ electric power. The characteristic testing circuit of the motor is shown in Fig. 2. The measurement apparatus that is installed at room temperature is connected to the cryogenic motor through ferro-fluid seal. Load is applied with a powder brake, and torque as well as speed is measured by a contactless type torque/speed meter. A three-phase auto transformer supplies the power to the motor, and a 3-phase power meter is used for measuring input voltage, current and power. Measured data are saved in a computer and waveforms are saved in a transient recorder.

\section{Air-Gap Magnetic Flux Density Distribution}

Fig. 3(a) shows the magnetic flux density distribution in the air-gap at room temperature. From the top to bottom in the

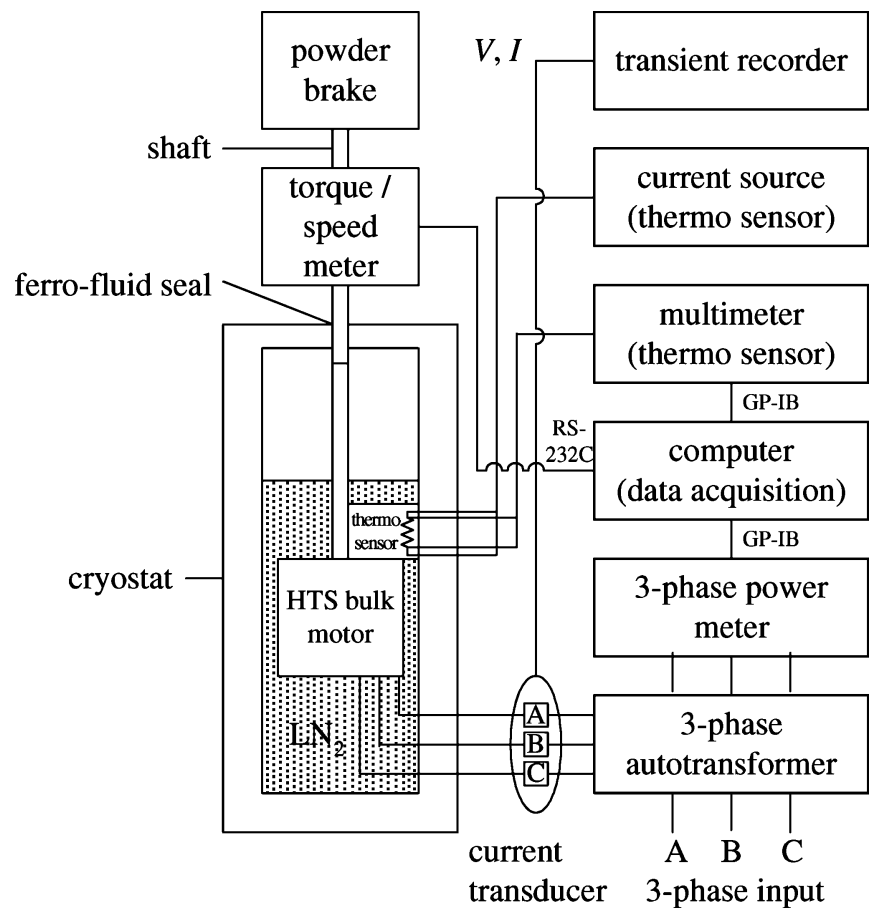

Fig. 2. Characteristic testing circuit of radial-type HTS bulk motor.

figure, measured time is delayed, respectively, at $2.78 \mathrm{~ms}$ (equivalent to $30^{\circ}$ in electrical angle). The dummy rotor is made of nonmagnetic material, and then reluctance between the stator and the rotor is large. Therefore, the magnetic flux density distribution is highly distorted due to the flux leakage between neighboring teeth cores.

Fig. 3(b) shows FFT analysis results of Fig. 3(a). Compared to the fundamental component, 11 th and 13th order components have large amplitude, which is independent of the measured time (i.e., electrical angle). As is already mentioned, 4-pole stator has 24 teeth, and the 12 teeth produce the 2-pole magnetic field distribution. Therefore, 11th and 13th order spatial harmonic components are resulted in large amplitude.

\section{Performance of Sintered Sm-123 Bulk Motor}

\section{A. No-Load Test}

Rotational speed, $N$, is measured as a function of phase voltage, $V_{\mathrm{s}}$ (or stator current, $I_{\mathrm{s}}$ ) under the no-load condition as shown in Fig. 4(a). By increasing $V_{\mathrm{s}}$, the torque is generated due to the magnetic flux penetration. And then, the motor starts rotating from $V_{\mathrm{s}}=50 \mathrm{~V}_{\mathrm{rms}}$. Firstly, $N$ increases in proportion to $V_{\mathrm{s}}$ at $V_{\mathrm{s}}<95 \mathrm{~V}_{\mathrm{rms}}$. At $V_{\mathrm{s}}>95 \mathrm{~V}_{\mathrm{rms}}$, however, the increasing rate of $N$ is suppressed, and $N$ does not reach the synchronous speed (1800 rpm) in the measured voltage/current range $\left(V_{\mathrm{s}}<165 \mathrm{~V}_{\mathrm{rms}}, I_{\mathrm{s}}<18 \mathrm{~A}_{\mathrm{rms}}\right)$.

As shown in Fig. 3, magnetic flux density distribution is highly distorted and large 11th and 13th order spatial harmonic components are included (the influence of Sm-123 bulk is not included). It is presumed that these harmonic components grow further under the motor operation, because of the shielding effect of Sm-123 bulk. Therefore, the torque which is generated by the 11th and 13th order spatial harmonic components, affects the large slippage. 


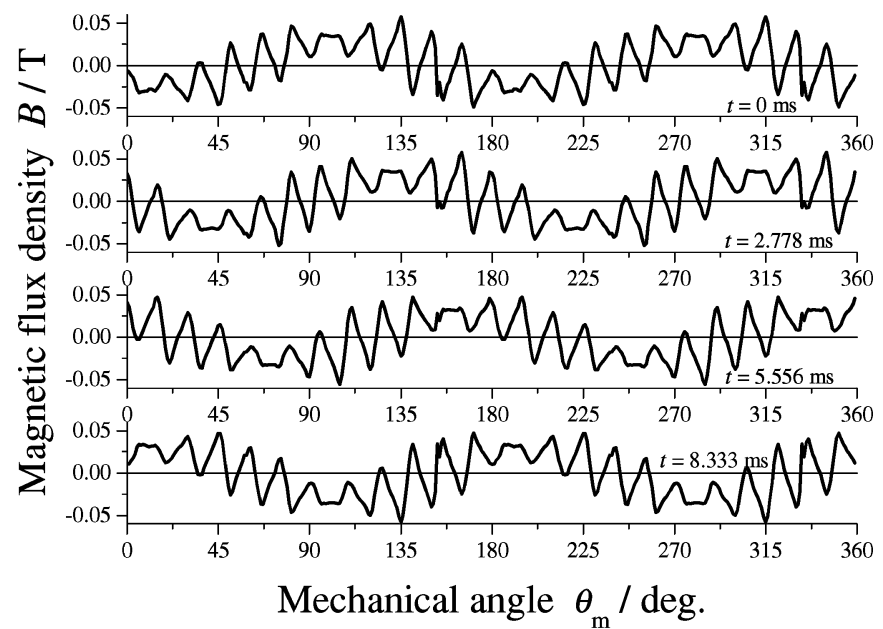

(a)

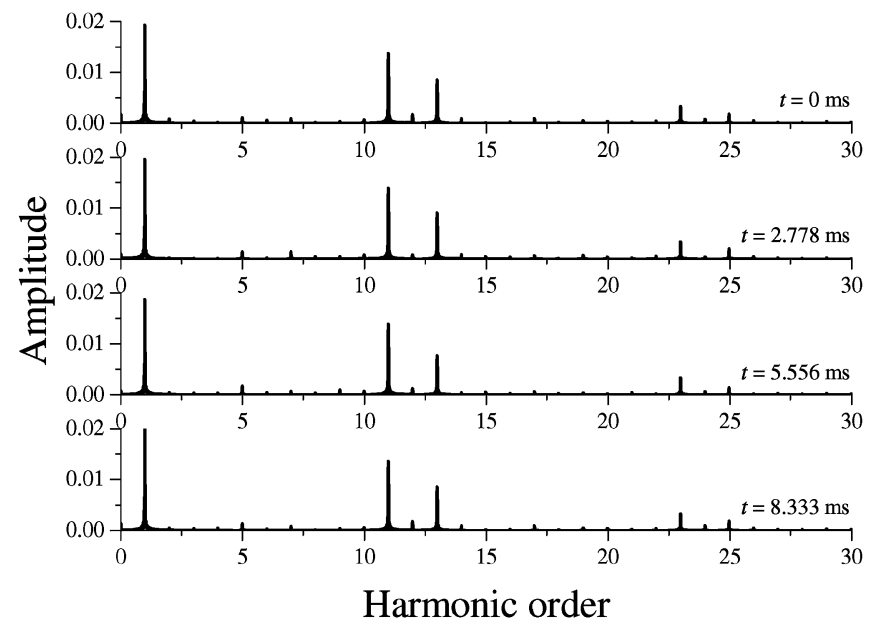

(b)

Fig. 3. Magnetic flux density distribution and spatial harmonics. (a) Air-gap magnetic flux density distribution; (b) spatial harmonic component.

\section{B. Locked Rotor Test}

Torque, $\tau$, is measured under the locked-rotor condition, i.e. the shaft of the rotor is fixed by the powder brake (see Fig. 2). $\tau$ vs. $I_{\mathrm{S}}$ characteristic is shown in Fig. 4(b). The inset shows the double logarithmic scale of the figure. As shown, $\tau$ is proportional to the square of $I_{\mathrm{s}}$, which is the characteristic of an induction motor. It is deduced that magnetic flux density is insufficient for the full penetration in the measured current/voltage range $\left(I_{\mathrm{s}}<12 \mathrm{~A}_{\mathrm{rms}}, V_{\mathrm{s}}<113 \mathrm{~V}_{\mathrm{rms}}\right)$. Therefore, the magnetic flux is partially penetrated into the surface of the Sm-123 bulk rotor, and the flux flow is induced. This flux flow current generates induction torque, and then the motor is operated as an induction motor. For the improvement of the Sm-123 bulk motor characteristics, the enhancement of magneto-motive-force and/or the reduction of Sm-123 bulk thickness (radial direction) are required.

\section{Load Test}

The torque, $\tau$, vs. rotational speed, $N$, relations are measured by increasing load with powder brake at $V_{\mathrm{s}}=75,95,113 \mathrm{~V}_{\mathrm{rms}}$ as shown in Fig. 4(c). As increasing $V_{\mathrm{s}}$, the flux penetration is enhanced and the corresponding $\tau$ is increased. However, $\tau$ is

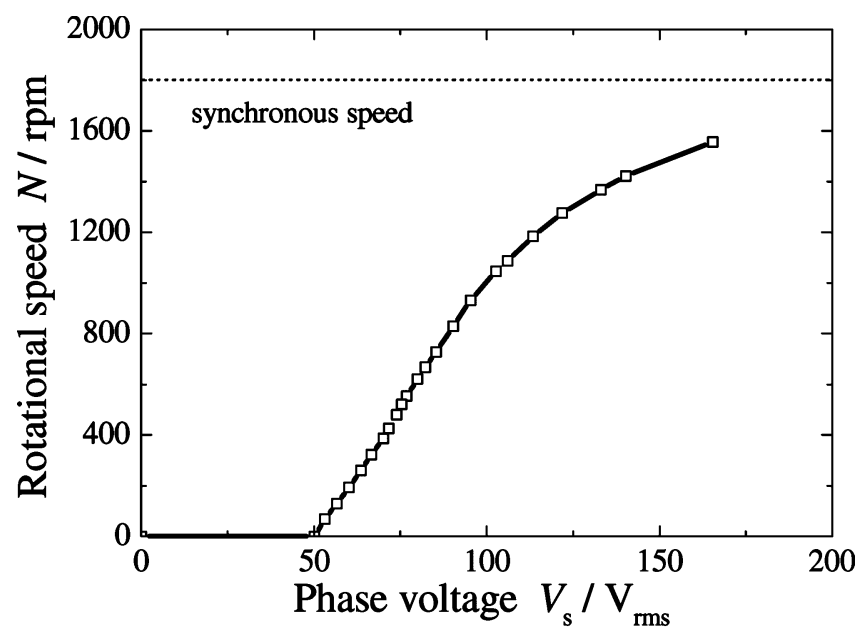

(a)

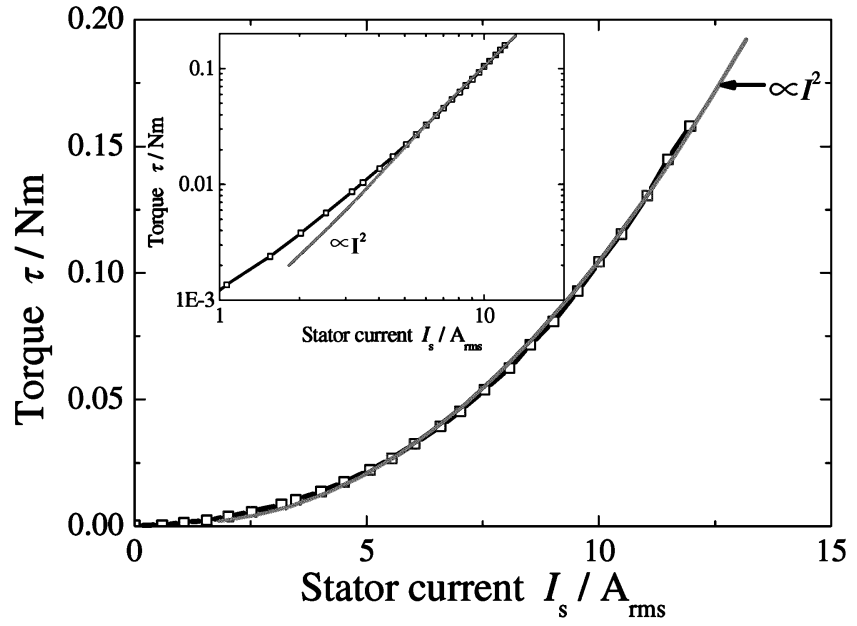

(b)

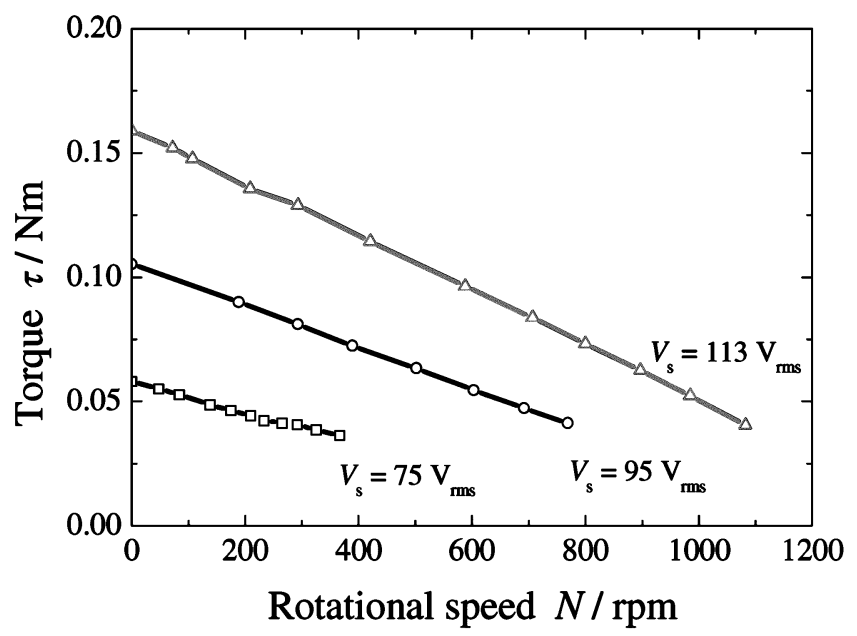

(c)

Fig. 4. Characteristics of radial type Sm-123 bulk motor. (a) No-load speed, $N$, vs. phase voltage, $V_{\mathrm{s}}$, characteristic; (b) standstill torque, $\tau$, vs. stator current, $I_{\mathrm{s}}$, characteristic; (c) torque, $\tau$, vs. speed, $N$, characteristics.

decreased as increasing $N$, and then the motor does not reach the synchronous speed (1800 rpm). That is, the Sm-123 bulk motor shows the characteristics of an induction motor which has large rotor resistance. Generally, the rotor resistance of an induction motor depends on rotational speed. The measured stator current 
is almost not varied as rotational speed, although load test is performed under the constant voltage condition. Because of the strong screening effect of the Sm-123 bulk rotor, the leakage flux between the stator and rotor side is large. Therefore, the input impedance is scarcely affected by the rotor resistance and the stator current keeps the constant value in spite of speed variation.

\section{CONCLUSION}

We have fabricated and tested the radial-type motor with the sintered Sm-123 bulk rotor. In the measured voltage/current range, the motor did not reach the synchronous speed, and the standstill torque was proportional to the square of the stator current. Moreover, the torque was decreased as increasing the rotational speed. Because of insufficient magneto-motive-force and spatial harmonic components in the air-gap magnetic flux density distribution, magnetic flux is prevented from penetrating into the Sm-123 bulk rotor. Therefore, the screening current in the rotor flows only on the surface of the rotor, and the motor showed the characteristics of an induction motor.

The fabricated motor showed unsatisfactory characteristics due to the insufficient magneto-motive-force. As a counter measure, the enhancement of magneto-motive-force and/or the reduction of Sm-123 bulk thickness are required.

\section{REFERENCES}

[1] M. D. McCulloch, K. Jim, Y. Kawai, and D. Dew-Hughes, "Prospects for brushless AC machines with HTS rotors," in Institute of Physics Conference Series, vol. 158, 1997, pp. 1519-1522.

[2] L. K. Kovalev, K. V. Ilushin, V. T. Penkin, K. L. Kovalev, V. S. Semenikhin, V. N. Poltavets, A. E. Larionoff, W. Gawalek, T. Habisreuther, T. Strasser, A. K. Shikov, E. G. Kazakov, and V. V. Alexandrov, "Hysteresis electrical motors with bulk melt-textured YBCO," Materials Science and Engineering B, vol. 53, pp. 216-219, 1998.

[3] G. J. Barnes, D. Dew-Hughes, and M. D. McCulloch, "Finite difference modeling of bulk high temperature superconducting cylindrical hysteresis machines," Supercond. Sci. Technol., vol. 13, pp. 229-236, 2000.
[4] L. K. Kovalev, K. V. Ilushin, V. T. Penkin, K. L. Kovalev, SM-A. Koneev, K. A. Modestov, S. A. Larionoff, W. Gawalek, and B. Oswald, "HTS electrical machines with YBCO bulk and Ag-BSCCO plate-shape HTS elements: recent results and future development," Physica $C$, vol. 354, pp. 34-39, 2001.

[5] L. K. Kovalev, K. V. Ilushin, V. T. Penkin, K. L. Kovalev, SM-A. Koneev, K. A. Modestov, S. A. Larionoff, W. Gawalek, and B. Oswald, "Electrical machines with bulk HTS elements: the achieved results and future development," Physica C, vol. 357-360, pp. 860-865, 2001.

[6] L. K. Kovalev, K. V. Ilushin, V. T. Penkin, K. L. Kovalev, SM-A. Koneev, K. A. Modestov, S. A. Larionoff, I. I. Akimov, and D. Dew-Hughes, "HTS electrical machines with BSCCO/Ag composite plate-shaped rotor elements," Physica C, vol. 372-376, pp. 1524-1527, 2002.

[7] L. K. Kovalev, K. V. Ilushin, K. L. Kovalev, V. T. Penkin, V. N. Poltavets, SM-A. Koneev, I. I. Akimov, W. Gawalek, B. Oswald, and G. Krabbes, "High output power electric motors with bulk HTS elements," Physica $C$, vol. 386, pp. 419-423, 2003.

[8] H. Ohsaki and Y. Tsuboi, "Study on electric motors with bulk superconductors in the rotor," Journal of Materials Processing Technology, vol. 108, pp. 148-151, 2001.

[9] Y. Tsuboi and H. Ohsaki, "Transient characteristics of a motor using high-Tc bulk superconductors in the rotor," Cryogenic Engineering, vol. 37, no. 11, pp. 704-711, 2002. (in Japanese).

[10] I. Muta, H. J. Jung, T. Hirata, T. Nakamura, T. Hoshino, and T. Konishi, "Fundamental experiments of axial-type BSCCO-bulk superconducting motor model," IEEE Trans. Appl. Supercond., vol. 11, pp. 1964-1967, 2001.

[11] I. Muta, H. J. Jung, T. Nakamura, and T. Hoshino, "Performance of axialtype motor with Bi-2223 HTS bulk rotor," Physica C, vol. 372-376, pp. 1531-1534, 2002.

[12] T. Nakamura, I. Muta, H. J. Jung, and T. Hoshino, "Electromagnetic characteristics of axial-type HTS motor utilizing a Bi-2223 bulk rotor," Cryogenic Engineering, vol. 37, no. 11, pp. 726-733, 2002. (in Japanese).

[13] H. J. Jung, T. Nakamura, I. Muta, and T. Hoshino, "Characteristics of axial-type HTS motor under different temperature conditions," IEEE Trans. Appl. Supercond., vol. 13, pp. 2201-2205, 2003.

[14] T. Nakamura, K. Fukui, H. J. Jung, I. Muta, and T. Hoshino, "Investigation of magnetic characteristics in HTS bulk materials for motor applications," IEEE Trans. Appl. Supercond., vol. 13, pp. 2255-2258, 2003.

[15] T. Nakamura, H. J. Jung, I. Muta, and T. Hoshino, "Steady state characteristics of axial-type Sm-123 bulk motor under different synchronous speed," in 6th European Conference on Applied Superconductivity, Sorrento-Napoli, Italy, September 14-18, 2003.

[16] H. J. Jung, T. Nakamura, N. Tanaka, I. Muta, and T. Hoshino, "Characteristic analysis of hysteresis-type $\mathrm{Bi}-2223$ bulk motor with the use of equivalent circuit," Physica C, vol. 405, pp. 117-126, 2004.

[17] T. Nakamura, H. J. Jung, I. Muta, and T. Hoshino, "Synchronization of axial-type Bi-2223 bulk motor operated in liquid nitrogen," Supercond. Sci. Technol, vol. 17, pp. 1319-1323, 2004. 